\title{
QUANTIFYING LOCATION-SPECIFIC IMPACTS OF PAVEMENT ALBEDO ON RADIATIVE FORCING USING AN ANALYTICAL APPROACH
}

Xin Xu ${ }^{a}$, Omar Sweib, Liyi Xu, C. Adam Schlosser ${ }^{c}$, Jeremy Gregory ${ }^{a}$, Randolph Kirchain ${ }^{d^{*}}$

${ }^{a}$ Department of Civil \& Environmental Engineering, Massachusetts Institute of Technology, Cambridge, MA 02139

${ }^{b}$ Department of Civil Engineering, University of British Columbia, CEME 2004C-6250 Applied Science Lane, Vancouver, BC Canada V6T $1 Z 4$

${ }^{c}$ Joint Program on the Science and Policy of Global Change, Massachusetts Institute of Technology, Building E19-439L, Cambridge, MA 02139

${ }^{d}$ Materials Research Laboratory, Massachusetts Institute of Technology, Building E19-695, Cambridge, MA 02139

* Corresponding author

Tel: (617)-253-4258 Email: kirchain@mit.edu (R Kirchain)

Contents

Pages: 8

Figures: $\quad 2$

Tables 7 


\section{S1. CALCULATING LOCATION-SPECIFIC RF IMPACTS}

To estimate the location-specific impacts of changes in pavement albedo we develop two estimates for all-sky $f_{a}$. The first uses a simple symmetric model (using observed data for $K_{T}$ and equation (6) from the body of the paper). The second estimate for all-sky $f_{a}$ derives from a novel parametric model. Together, these two methods yield upper and lower bounds of the all-sky $f_{a}$ value, and consequently an estimate of the range for GWP. This section describes the development of the parametric model and the application of both symmetric and parametric modeled $f_{a}$ to estimate GWP.

A two model approach to estimating transmittance factor $\boldsymbol{f}_{\boldsymbol{a}}$ under all sky conditions To develop a model for all-sky $f_{a}$, we explored many different model forms to estimate $c f$. Overall, we group these into two major approaches. The first, labeled the two model approach, is similar to the approaches of Anslow et al., Foyo-Moreno et al., and Pellicciotti et al. ${ }^{1-3}$, This approach makes use of one model to estimate $K_{T}^{\text {clear }}$ and subsequently uses that model and observed data on $K_{T}$ to develop a dataset of $c f$. Then a second model is then developed to estimate $c f$. The second approach, the onemodel approach, involves creating a single model of $K_{T}$, then using that same model to estimate $K_{T}^{\text {clear }}$ and, therefore, $c f$. Because we found better model performance using the one model approach, we describe it in detail in the body of the paper. Here we describe the two-model approach.

Following the approach of $\mathrm{Li}$ and Garand, we model $K_{T_{-} \text {clear }}$ as a function of precipitable water $p w$, and cosine of solar zenith angle $c z$. We use the data set described in the body of the text for $K_{T}$ filtered for days with a cloudiness index $(\mathrm{Cl})<=0.01$. We observed a good correlation among clear-sky transmittance (for $\mathrm{Cl}$ $<=0.01$ ), precipitable water $p w$, and cosine of solar zenith angle $c z$ (R-squared $>0.8$ ) using the model:

$$
\widehat{K_{T}^{\text {clear }}}=\alpha \cdot C z \cdot \beta \cdot p w^{0.5}+\gamma \quad(\text { for } C l<=0.01)
$$

We use $\widehat{K_{T}^{\text {clear }}}$ as a reminder that it is our estimate of clear-sky transmittance. This led to the best fit coefficients shown in Table SI 1. 
Table SI 1. Best fit parameters for equation SI.1. Values in parentheses are t-statistics.

\begin{tabular}{|c|c|c|c|c|}
\hline & $C Z$ & $p w^{0.5}$ & Constant & $R^{2}$ \\
\hline Miami & $\begin{array}{l}.1239361 \\
(88.12) \\
\end{array}$ & $\begin{array}{l}-.0167484 \\
(-86.20) \\
\end{array}$ & $\begin{array}{l}.7534132 \\
(685.29) \\
\end{array}$ & 0.9453 \\
\hline Houston & $\begin{array}{l}.1665392 \\
(10.30) \\
\end{array}$ & $\begin{array}{l}-.0289151 \\
(-16.16) \\
\end{array}$ & $\begin{array}{l}.7612896 \\
(79.23) \\
\end{array}$ & 0.8962 \\
\hline Atlanta & $\begin{array}{l}.2129095 \\
(4.41) \\
\end{array}$ & $\begin{array}{l}-.0469574 \\
(-8.43)\end{array}$ & $\begin{array}{l}.768732 \\
(22.16) \\
\end{array}$ & 0.8537 \\
\hline Phoenix & $\begin{array}{l}.1101946 \\
(70.41)\end{array}$ & $\begin{array}{l}-.0226678 \\
(-74.87)\end{array}$ & $\begin{array}{l}.8119063 \\
(776.26)\end{array}$ & 0.9034 \\
\hline Los Angeles & $\begin{array}{l}.1275022 \\
(6.45)\end{array}$ & $\begin{array}{l}-.0291818 \\
(-6.97)\end{array}$ & $\begin{array}{l}.7848218 \\
(46.00)\end{array}$ & 0.9101 \\
\hline San Francisco & $\begin{array}{l}.1227344 \\
(17.45)\end{array}$ & $\begin{array}{l}-.0216449 \\
(-16.41)\end{array}$ & $\begin{array}{l}.76768 \\
(117.84)\end{array}$ & 0.8778 \\
\hline Baltimore & $\begin{array}{l}.1323264 \\
(3.17)\end{array}$ & $\begin{array}{l}-.0482372 \\
(-7.13)\end{array}$ & $\begin{array}{l}.8305127 \\
(30.86)\end{array}$ & 0.8661 \\
\hline Nashville & $\begin{array}{l}.2244233 \\
(6.15)\end{array}$ & $\begin{array}{l}-.0403304 \\
(-8.18)\end{array}$ & $\begin{array}{l}.7411301 \\
(26.66)\end{array}$ & 0.8247 \\
\hline St. Louis & $\begin{array}{l}.1806597 \\
(8.15)\end{array}$ & $\begin{array}{l}-.0408996 \\
(-13.81)\end{array}$ & $\begin{array}{l}.7787647 \\
(61.86)\end{array}$ & 0.8603 \\
\hline Seattle & $\begin{array}{l}.1556456 \\
(62.89) \\
\end{array}$ & $\begin{array}{l}-.0173053 \\
(-36.55) \\
\end{array}$ & $\begin{array}{l}.7296215 \\
(376.72) \\
\end{array}$ & 0.9304 \\
\hline Boston & $\begin{array}{l}.1126258 \\
(2.94) \\
\end{array}$ & $\begin{array}{l}-.0347503 \\
(-6.25)\end{array}$ & $\begin{array}{l}.8374543 \\
(27.96) \\
\end{array}$ & 0.8320 \\
\hline Denver & $\begin{array}{l}.0989638 \\
(5.17) \\
\end{array}$ & $\begin{array}{l}-.0216835 \\
(-5.90) \\
\end{array}$ & $\begin{array}{l}.798629 \\
(74.20) \\
\end{array}$ & 0.8129 \\
\hline Minneapolis & $\begin{array}{l}.2016411 \\
(7.15) \\
\end{array}$ & $\begin{array}{l}-.0350188 \\
(-8.33) \\
\end{array}$ & $\begin{array}{l}.7326137 \\
(53.43) \\
\end{array}$ & 0.8528 \\
\hline Duluth & $\begin{array}{l}.1426475 \\
(6.26)\end{array}$ & $\begin{array}{l}-.0237859 \\
(-7.85)\end{array}$ & $\begin{array}{l}.7514691 \\
(43.60)\end{array}$ & 0.8490 \\
\hline
\end{tabular}

Next, we compute the cloud transmittance factor $(c f)$, as the ratio of observed $K_{T, i}$ for $\mathrm{Cl}>0.01$ to $\widehat{K_{T, i}^{\text {clear }}}$ for the same day:

$$
c f_{i}=\frac{K_{T, i}}{\widehat{K_{T, i}^{\text {clear }}}}
$$

Figure S1 shows the calculated daily cloud transmittance factor $c f_{i}$ together with cloud fraction cld, the diurnal temperature range $\Delta T$ and the cosine of solar zenith angle $c z$ for Phoenix. As expected, the cloud transmittance factor, $c f$, is clearly correlated with cloud fraction cld, with a correlation coefficient of -0.74 . For example, a low cloud transmittance factor on 27 Jan, indicated by the dashed line in Figure S1, corresponds to an overcast condition with high cloud fraction, whereas the correspondence is less clear for $\Delta T$ and $c z$ (correlation coefficient are 0.49 and 0.34 , respectively). 


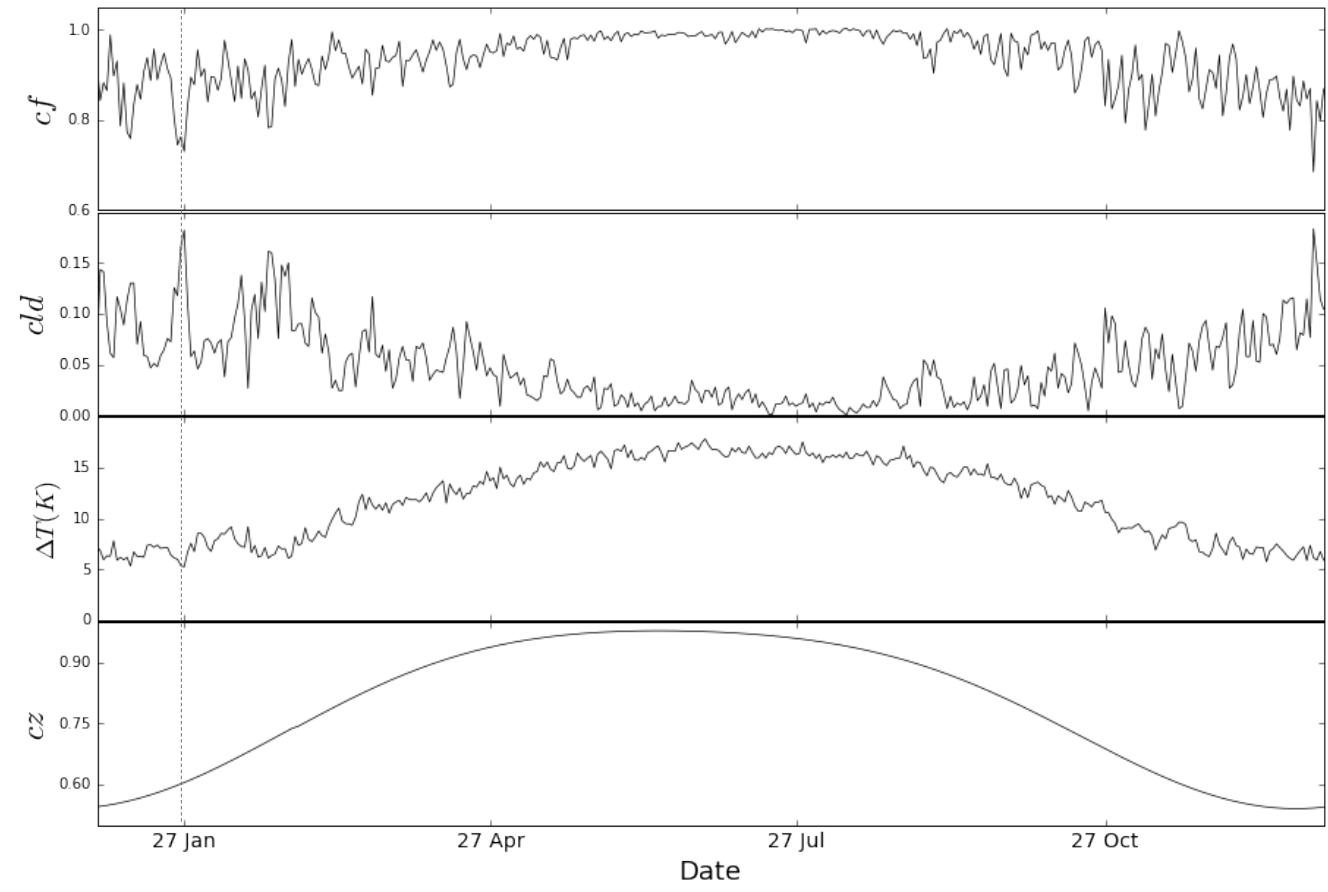

Figure S1. Daily cloud transmittance factors cf, together with daily cloud fraction cld, diurnal temperature range $\Delta T$, and cosine of solar zenith angle $c z$. Dashed line denotes data for the $27^{\text {th }}$ of January.

We examined a range of linear and non-linear models to best estimate $c f$ using the three variables mentioned above. Specifically, following Pellicciotti we tested linear, exponential, polynomial, and Gausian forms. Unlike previous work, we expand the set of linear models to include forms with interaction terms. R-squared is used as an indication of the goodness of fit. Table SI 2 lists the parameterization results for all the models tested. Generally, different models perform similarly with Rsquared values between 0.55 (Linear 1 - linear function with only one independent variable cloud) and 0.57 (Linear 2 and 3 - linear function with interaction term). It should be noted that cloud fraction itself explains $55.3 \%$ of the total variance. Polynomial, exponential, and Gaussian models yield similar $\mathrm{R}^{2}$ values but they are more complicated in form. 
Table SI 2. Regression models used in the regression analysis between the independent variables cloud fraction cld, cosine of solar zenith angle $c z$, and diurnal temperature range $\Delta T$ as independent variables and the dependent variable daily cloud transmittance factor cf. Also shown are the values of the coefficients and corresponding $R$-squared values for the regression equations that best fit to data pooled from WRF simulations.

\begin{tabular}{llcc}
\hline \multicolumn{1}{c}{ Models } & $\boldsymbol{c f} \boldsymbol{f}=\boldsymbol{g}(\boldsymbol{c l o u} \boldsymbol{d})=\boldsymbol{f}(\boldsymbol{c l d}, \boldsymbol{c z}, \Delta \boldsymbol{T})$ & Coefficients & $\mathbf{R}^{\mathbf{2}}$ \\
\hline Linear 1 & $c f=a \cdot$ cloud $+b$ & $-1.25,1.00$ & 0.553 \\
Linear 2 & $c f=a \cdot$ cloud $+b \cdot c z+c$ & $-1.19,0.097,0.915$ & 0.566 \\
Linear 3 & $c f=a \cdot c l o u d+b \cdot c z+c \cdot \Delta T+d$ & $-1.17,0.083,0.001,0.917$ & 0.566 \\
Polynomial & $c f=a \cdot$ cloud ${ }^{2}+b \cdot c l o u d+c$ & $1.38,-1.63,1.00$ & 0.563 \\
Linear w/ & $c f=a \cdot$ loud $+b \cdot c z+c \cdot$ cloud $\cdot c z+d$ & $-1.86,0.06,0.97,0.95$ & 0.576 \\
interaction term & & 462.06 & 0.547 \\
Exponential & $c f=1-\exp (-a \cdot c l o u d)$ & $2.2 \mathrm{E} 05,-16.14,4.6$ & 0.567 \\
Gaussian & $c f=a \cdot \exp \left[-\left(\frac{c l o u d-b}{c}\right)^{2}\right]$ &
\end{tabular}

Because the values of $c f$ exhibit significant heteroscedasticity, final models were fit using weighted least squares regression. Different types of weighting were evaluated including weighting by absolute values, log of squared residuals, squared residuals and squared fitted values. The one that performs the best is making the adjustment proportional to the squared fitted values of cloud fraction cloud. The resulting weighted residual plot for the case of Phoenix is shown in Figure S2, which clearly demonstrates the improvement by reducing the heteroscedasticity. The WLS regression model that includes an interaction term has the following coefficients with an R-squared of 0.616 .

$$
\widehat{c f}=-1.54 \text { cloud }+0.09 c z+0.65 \text { cloud } \cdot c z+0.92
$$
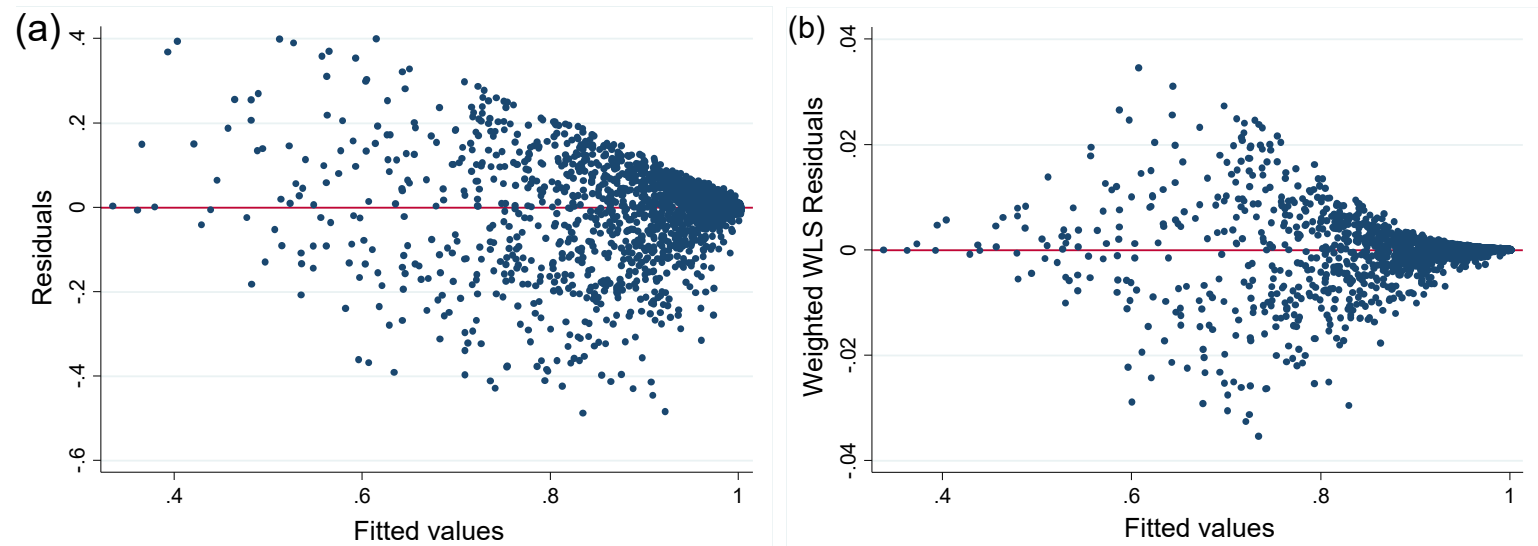

Figure S2. Weighted residual plot for cf predicted from WLS regression model for Phoenix 


\section{S2. Estimating the Urban Canyon Transmittance $(\tau)$}

For the case analyses in this paper, we estimate the urban canyon transmittance (also known as sky view factor) ( $\tau$ ) using the values shown in Table SI 3. First of all, we take average sky view factors for neighborhood types (referred to as local climate zones or LCZs) from Stewart and Oke. ${ }^{4}$ (Numbers in top row.) Second, we take the breakdown in urban neighborhood type distribution from USGS land-use analyses. ${ }^{5}$ (Numbers in first column in percent.). Note that based on the USGS analysis about 3\% of land in the US is found in dense developed areas. Next, based on the authors' expert judgement, each land use classification is assigned to a distribution of LCZs. (Black numbers in central panel of the table.) The weighted average $\tau$ value is computed for each land use classification (row) and reported in the rightmost column of the table (Values at right of table.) Finally, we compute a weighted average of these $\tau$ values based on the prevalence of land use type. This value is the bold value reported in the right, bottom corner of the table.

Finally, we adopt a shading factor of 0.9 for rural roads as a value above the sparse housing LCZ value reported by Stewart and Oke ${ }^{4}$, but not quite at 1.

Table SI 3. Calculation of average urban canyon transmittance.

\begin{tabular}{|c|c|c|c|c|c|c|c|c|c|c|}
\hline & & & & & & & & & & \\
\hline & & & & Loc & Clim & te Zon & e (LCZ) & & & \\
\hline & & 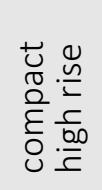 & 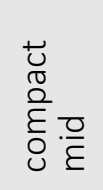 & 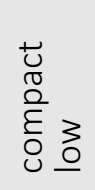 & 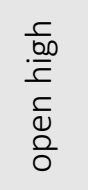 & $\begin{array}{l}\frac{\bar{\sigma}}{\varepsilon} \\
\bar{\emptyset} \\
\frac{\tilde{\nu}}{0}\end{array}$ & $\begin{array}{l}\frac{3}{0} \\
\frac{c}{0} \\
\frac{0}{0}\end{array}$ & $\begin{array}{l}3 \\
0 \\
0 \\
000 \\
\frac{0}{0} \\
-0\end{array}$ & $\begin{array}{l}\frac{1}{\omega} \\
\frac{\omega}{\pi} \\
\frac{0}{\infty} \\
\frac{0}{n}\end{array}$ & \\
\hline & & LCZ & LCZ & LCZ & LCZ & LCZ & LCZ & LCZ & LCZ & \\
\hline & & 1 & 2 & 3 & 4 & 5 & 6 & 8 & 9 & \\
\hline Land Use Classification (LUC) & \% Land Use & 0.3 & 0.45 & 0.4 & 0.6 & 0.65 & 0.75 & 0.7 & 0.8 & $\begin{array}{c}\text { Weighted } \\
\text { Average SVF }\end{array}$ \\
\hline Developed, Commercial/Services & 0.46 & & & & & & & $100 \%$ & & 0.70 \\
\hline Developed, Industrial/Military & 0.23 & & & & & & $100 \%$ & & & 0.75 \\
\hline Developed, Recreation & 0.19 & & & & & & & & $100 \%$ & 0.80 \\
\hline Developed, Residential, High Density & 0.53 & $33 \%$ & $33 \%$ & $33 \%$ & & & & & & 0.38 \\
\hline Developed, Residential, Low-Medium Density & 1.20 & & & & & $33 \%$ & $33 \%$ & & $33 \%$ & 0.73 \\
\hline Developed, Other & 0.39 & $13 \%$ & $13 \%$ & $13 \%$ & $13 \%$ & $13 \%$ & $13 \%$ & $13 \%$ & $13 \%$ & 0.58 \\
\hline & & & & & & Ove & all Aver & age Urk & an SVF & 0.65 \\
\hline
\end{tabular}




\section{S3. Estimating Average Vehicle Coverage of Roadways}

To estimate average vehicle coverage of urban and rural roadways, we rely on data provided by the Federal Highway Administration (FHWA) ${ }^{6}$. FHWA provides aggregate data on vehicle miles travelled (VMT) in the United Stated by vehicle type as shown in Table SI 2. Using typical vehicle length and width information, it can be estimated that the average vehicle covers $18.95 \mathrm{~m}^{2}$ of paved surface at any point in time.

Table SI 4. Vehicle miles travelled (VMT) in the United States in 2017 and typical length and width of different vehicle types ${ }^{3}$.

\begin{tabular}{|l|c|c|c|c|}
\hline Vehicle Class & $\begin{array}{c}\text { Vehicle Miles Travelled } \\
\text { (Millions) }\end{array}$ & Proportion & $\begin{array}{c}\text { Typical Length } \\
(\mathrm{m})\end{array}$ & $\begin{array}{c}\text { Typical Width } \\
(\mathrm{m})\end{array}$ \\
\hline Light Duty Vehicle & 2220801 & $69 \%$ & 6 & 2.5 \\
\hline Motor-Cycles & 20149 & $1 \%$ & 1 & 0.5 \\
\hline Buses & 17227 & $1 \%$ & 2.5 & 12.5 \\
\hline Light Duty Vehicles Long & 656578 & $20 \%$ & 2.5 & 9 \\
\hline Single-Unit Truck & 116102 & $4 \%$ & 12.5 & 2.5 \\
\hline Combination Trucks & 181490 & $6 \%$ & 19 & 2.5 \\
\hline
\end{tabular}

Using the same FHWA data, we are also provided vehicle-miles travelled and total lane-miles in the United States in 2017 based on road type (Table SI3). Assuming that a typical lane is 12 feet (3.66 meters) wide, there are a total of 19,922 (6,221 urban and 13,701 rural) square miles of public roads in the United States.

Table SI 5. VMT across the United States in 2017, total lane-miles of roads, and free flow speed of different roadway types ${ }^{3}$

\begin{tabular}{|c|c|c|c|c|}
\hline & Roadway Type & $\begin{array}{l}\text { Vehicle Miles Travelled } \\
\text { (Millions) }\end{array}$ & Lane-Miles & $\begin{array}{l}\text { Free Flow Speed } \\
\text { (MPH) }\end{array}$ \\
\hline \multirow{7}{*}{$\begin{array}{l}\overline{\frac{\pi}{J}} \\
\stackrel{\partial}{x}\end{array}$} & Interstate & 252,550 & 119,193 & 65 \\
\hline & Other Freeways and Expressways & 36,526 & 25,421 & 55 \\
\hline & Other Principal Arterial & 190,989 & 231,903 & 40 \\
\hline & Minor Arterial & 144,878 & 276,869 & 35 \\
\hline & Major Collector & 160,445 & 818,982 & 25 \\
\hline & Minor Collector & 44,655 & 522,649 & 25 \\
\hline & Local & 133,162 & $4,033,365$ & 25 \\
\hline \multirow{7}{*}{ 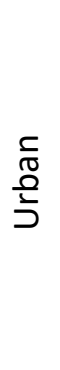 } & Interstate & 567,210 & 105,745 & 65 \\
\hline & Other Freeways and Expressways & 251,152 & 57,297 & 55 \\
\hline & Other Principal Arterial & 482,738 & 237,514 & 40 \\
\hline & Minor Arterial & 410,196 & 295,246 & 35 \\
\hline & Major Collector & 206,209 & 277,764 & 25 \\
\hline & Minor Collector & 17,141 & 37,524 & 25 \\
\hline & Local & 314,495 & $1,726,107$ & 25 \\
\hline
\end{tabular}


Using the values provided in Table SI 2 and Table SI 3, we can compute the average daily vehicle coverage of urban and rural paved surfaces via a few assumptions. Namely, we assume that the average day over a year is 13 hours long, that urban roads are subject to $30 \%$ congestion, and that $95 \%$ of vehicular traffic occurs during daylight hours. As shown in Table SI 4 and Table SI 5, we estimate that the average daily vehicle coverage during daylight hours as $0 \%$ for rural pavements and $2 \%$ for urban roadways. We use these values to generate our case study results shown in Figure 4.

Table SI 6. Calculation of average daily coverage of rural roads during daylight hours.

\begin{tabular}{|l|c|c|}
\hline Exposed Pavement During Day & $10,686,780$ & Square Mile Minutes \\
\hline VMT per Day & $2,637,114,305$ & Miles \\
\hline Average Vehicle Speed & 41 & MPH \\
\hline Vehicle Minutes per Day & $3,849,432,936$ & Minutes \\
\hline Vehicle Coverage & 18.95 & $\mathrm{~m}^{2}$ \\
\hline Vehicle Coverage Over 24-Hours & 28,169 & Square Mile Minutes \\
\hline Vehicle Coverage During Day & 26,760 & Square Mile Minutes \\
\hline Daily Vehicle Coverage & $0 \%$ & $\%$ \\
\hline
\end{tabular}

Table SI 7. Calculation of average daily coverage of urban roads during daylight hours.

\begin{tabular}{|l|c|c|}
\hline Exposed Pavement During Day & $4,852,380$ & Square Mile Minutes \\
\hline VMT per Day & $6,157,815,195$ & Miles \\
\hline Average Vehicle Speed (No Stoppage) & 43 & MPH \\
\hline Average Vehicle Speed (Stoppage) & 30 & MPH \\
\hline Vehicle Minutes per Day & $12,138,975,827$ & Minutes \\
\hline Vehicle Coverage & 18.95 & $\mathrm{~m}^{2}$ \\
\hline Vehicle Coverage Over 24-Hours & 88,829 & Square Mile Minutes \\
\hline Vehicle Coverage During Day & 84,388 & Square Mile Minutes \\
\hline Daily Vehicle Coverage & $2 \%$ & $\%$ \\
\hline
\end{tabular}




\section{S4. Bibliography}

1. Anslow, F. S., Hostetler, S., Bidlake, W. R. \& Clark, P. U. Distributed energy balance modeling of South Cascade Glacier, Washington and assessment of model uncertainty. J. Geophys. Res. 113, F02019 (2008).

2. Foyo-Moreno, I., Alados, I., Olmo, F. J., Vida, J. \& Alados-Arboledas, L. On the use of a cloud modification factor for solar UV $(290 \pm 385 \mathrm{~nm})$ spectral range. Theor. Appl. Climatol. $68,41-50$ (2001).

3. Pellicciotti, F., Raschle, T., Huerlimann, T., Carenzo, M. \& Burlando, P. Transmission of solar radiation through clouds on melting glaciers: a comparison of parameterizations and their impact on melt modelling. J. Glaciol. 57, 367-381 (2011).

4. Stewart, I. D. \& Oke, T. R. Local Climate Zones for Urban Temperature Studies. Bull. Am. Meteorol. Soc. 93, 1879-1900 (2012).

5. Falcone, J. A. U.S. conterminous wall-to-wall anthropogenic land use trends (NWALT), 1974-2012. U.S. Geological Survey Data Series (2015). doi:10.3133/ds948

6. Highway Statistics 2017,. Office of Highway Policy Information (2018). Available at: https://www.fhwa.dot.gov/policyinformation/statistics/2017/. (Accessed: 15th January 2019) 